\title{
EDUCAÇÁO EM GÊNERO E DIVERSIDADE SEXUAL E LGBTIFOBIA NAS ESCOLAS: DESCONSTRUÇÃO DO BULLYING AO CRIME
}

\author{
Antônio Rodrigues Neto ${ }^{1}$ \\ Universidade Federal de Mato Grosso do Sul (UFMS) \\ Marco Antônio Carrasco ${ }^{2}$ \\ Universidade Federal de Mato Grosso do Sul (UFMS)
}

Artigo recebido em: 22/10/2019.

Artigo aceito em: 14/11/2019.

\section{Resumo}

O presente artigo tem como objetivo demonstrar de que maneira a Educação em Gênero e Diversidade Sexual pode servir ao enfrentamento do bullying escolar contra pessoas LGBTI, considerando a possibilidade de penalizaçáo das práticas LGBTIfóbicas, a partir de Decisão do STF que associou a discriminaçáo com base em gênero e sexualidade ao racismo. Desse modo, por meio de pesquisa bibliográfica e documental e aplicando o método dedutivo, analisou-se o bullying enquanto ofensa a Direitos Humanos, seus impactos para a formação da cidadania e o respeito à diferença. Como resultados, observa-se que a criminalização, por si só, não promove a inclusão, sendo necessário rever causas estruturais do problema antes que seja praticado o crime. A escola é o espaço ideal para isso.

Palavras-chave: bullying; criminalização da LGBTIfobia; educação em gênero e diversidade sexual.

1 Mestre em Direitos Humanos pela UFMS. ORCID: https://orcid.org/0000-0001-8402-7267/e-mail: antonio. neeeto@gmail.com

2 Graduando em Direito pela UFMS. E-mail: marco.antonio.carrasco@hotmail.com 


\section{GENDER AND SEXUAL DIVERSITY EDUCATION AND LGBTIPHOBIA IN SCHOOLS: BULLYING DECONSTRUC- TION TO CRIME}

\section{Abstract}

This article aims to demonstrate how Gender and Sexual Diversity Education can serve to confront school bullying against LGBTI people, considering the possibility of penalizing LGBTIphobic practices, based on a Supreme Court's decision that associated gender and sexuality discrimination with racism. Thus, from bibliographic and documentary research and applying the deductive method, bullying as an offense to human rights, its impacts on citizenship

formation and respect for difference were analyzed. As a result, it is observed that criminalization by itself does not promote inclusion, and it is necessary to review structural causes of the problem before the crime is committed. School is the ideal place for this.

Keywords: bullying; criminalization of LGBTIphobia; gender and sexual diversity education. 


\section{Introdução}

Entender de que maneira as questóes da identidade, especialmente aquelas constituídas sobre o gênero e a sexualidade, interferem no nível de participação social dos indivíduos tem sido um desafio ao Direito. Enquanto elementos inerentes à personalidade humana e, portanto, com inevitáveis reflexos jurídicos, a construção social do gênero (BUTLER, 2003, p. 25) e as inúmeras possibilidades de manifestação desse gênero e da sexualidade no tecido social apresentam uma abstração conceitual e prática que causa estranheza ao mundo das leis. Em razão disso, a luta por direitos e inclusão das minorias sexuais é um fenômeno global e tema de Direitos Humanos (PIOVESAN, 2016).

Se, por um lado, o preâmbulo constitucional (BRASIL, 1988) propóe que a Democracia brasileira se destine a assegurar, entre outros, o exercício da liberdade, bem-estar e igualdade entre seus cidadãos, para que assim se alicerce um Estado fraterno e sem preconceitos, quanto mais distante estiver do ideal masculino, hétero e cisnormativo (e, ainda, branco e de classe média ou classe alta), por outro, maiores as chances de que - em algum espaço público ou privado - um indivíduo seja limitado/tolhido em sua igualdade material (BAHIA, 2017, p. 35). Ainda que haja a previsão de igualdade material e formal entre todas as pessoas, como compreender as diferenças a ponto de neutralizar/eliminar desigualdades?

A (re)existência de mulheres e pessoas LGBTI, portanto, especialmente quando interseccionalizada a recortes étnico-raciais, de classe econômica e condiçôes físicas e mentais, está associada, cada qual a seu modo, à restrição de dignidade humana, supressão de garantias fundamentais e do acesso a espaços e direitos (MOREIRA, 2017a, p. 147), entre os quais se destacam a negação ou limitação ao direito de escolarização, de acesso e reconhecimento profissional nos ambientes de trabalho, de segurança, de domínio sobre o próprio corpo, de respeito ao nome e identidade, etc.

No Brasil, têm sido recorrentes as discussóes públicas geradas a partir dos índices de violência, da luta pela feminina por sua emancipação e do julgamento, pelo Supremo Tribunal Federal (STF), de casos envolvendo a tutela de direitos a pessoas $\mathrm{LGBTI}^{3}$. No que se refere especificamente às decisôes da Corte Superior, o entendimento constitucional hodiernamente construído equipara as relaçôes entre pessoas de mesmo sexo à relação de união estável (BRASIL, 2011), permite que transexuais alterem o prenome e o sexo do registro civil sem a necessidade de

3 Opta-se pela utilizaçáo da sigla LGBTI para definir o movimento de Lésbicas, Gays, Bissexuais, Transgêneros (travestis e transexuais) e Intersexos, por ser aquela utilizada pelas Naçóes Unidas no Brasil (NAÇŌES UNIDAS DO BRASIL, 2019). Todavia, reconhece-se a existência - e relevância - de outras variaçốes da sigla, que objetivam englobar todos que sofrem discriminação em razão de sua orientação sexual ou da forma como manifestam/reconhecem seu gênero. 
cirurgia ou laudo médico (BRASIL, 2018) e que o crime de racismo seja aplicado em casos de atos atentatórios a direitos fundamentais de pessoas LGBTI (BRASIL, 2019).

A criminalização da LGBTIfobia ${ }^{4}$, como ficou conhecida a decisão que reconheceu a omissão inconstitucional legislativa pela não criminalização dos atos de homofobia e transfobia (BRASIL, 2019), ainda que simbolize a expansão da tutela estatal sobre pessoas LGBTI no Brasil, expóe inquietaçóes jurídicas 5 que justificam a presente pesquisa: a primeira, de cunho legal, refere-se à possibilidade de revogação da proteção conquistada em caso de elaboração de lei com entendimento contrário; a segunda, de cunho socioeducativo, questiona se a mera criminalização, por si só, tem o condão de superar as causas estruturais que levam à manutenção da cultura LGBTIfóbica, a qual está presente até mesmo nas instituiçôes estatais, sendo, para tanto, necessário ainda que concepçóes mais humanas e inclusivas sobre o gênero e a sexualidade sejam assimiladas pela sociedade para, entâo, transformá-la.

A educação, nesse sentido, desponta como instrumental poderoso na transformação cultural do gênero e da sexualidade, uma vez que à escola foi dada a função de formar para a cidadania (BRASIL, 1988), de modo que todos os educandos devem, além de capacitar-se científica e tecnicamente, aprender a desempenhar papéis na qualidade de atores públicos e privados, reconhecer-se como sujeito de direitos e respeitar regras indispensáveis à vida em coletividade. Além disso, a sala de aula é onde o estudante deve encontrar meios para alcançar seu desenvolvimento pleno (BRASIL, 1988), formando sua identidade e conquistando sua consciência e autonomia.

Considerando que, em uma perspectiva sociológica, as disputas envolvendo o gênero e a sexualidade são marcadas por relaçôes de poder e resistência ${ }^{6}$, resultando em diferentes níveis de integração social, bem como a lentidáo do processo de desconstrução de estigmas e de superação das desigualdades que norteiam o assunto, ensinar o respeito à diferença na escola, assim é expandir o sentimento de pertença à tutela de um ordenamento jurídico no qual qualquer pessoa - independentemente do gênero ou da orientação sexual - tenha direitos e deveres e reconheça a si mesma e seu próximo em sua dignidade.

4 É essencial que a dominação androcêntrica e cisgênero seja repensada em todos os espaços e, principalmente, dentro das pautas do Movimento LGBTI. Para melhor desenvolvimento textual, opta-se pela substituiçấo dos termos "homofobia" e "transfobia" e utilizaçăo do termo "LGBTIfobia", sem intenção de comparar ou generalizar os conceitos, mas como mecanismo de inclusão das diferentes ofensas a Direitos Humanos que perpassa a existência dessas pessoas.

5 Para Piovesan (2016, p. 416), "Incorporar a perspectiva de gênero na doutrina jurídica brasileira impóe, sobretudo, o desafio de mudança de paradigmas. Esse desafio aponta a necessidade de introjetar novos valores e uma nova visão de Direito, de sociedade e de mundo. Traduz também a necessidade de inclusão de grande parte da população mundial e da inclusão de seu modo de perceber e compreender a realidade".

6 Nesse sentido, reconhece Foucault (1995, p. 248) que "[...] não há relação de poder sem resistência, sem escapatória ou fuga, sem inversão eventual; toda relação de poder implica, pelo menos de modo virtual, uma estratégia de luta”. 
Nesse sentido, a abordagem da diferença na escola (seja ela de gênero, sexualidade, características étnico-raciais, de classe econômica ou de condiçóes físicas e mentais) (PEREIRA; VARELA; SILVEIRA, 2015, p. 1491), portanto, torna-se mecanismo de expansão da cidadania, pois consagra o "direito a ter direitos" citado por Arendt (2012, p. 403), marco teórico empregado na discussão.

O bullying entre alunos, por sua vez, além de representar um problema pedagógico que demanda atenção de todo corpo escolar, da família, do poder público e da sociedade em geral, é violência psicológica (e, em alguns casos, física) fundada em discriminaçóes estruturais que hierarquizam a diferença desde a escola e que necessitam ser revisitadas sob uma perspectiva de Educação em Direitos Humanos.

Diante da recente criminalização das práticas LGBTIfóbicas pelo STF, este artigo - que integra parte de pesquisa de Mestrado beneficiada com bolsa da Coordenação de Aperfeiçoamento de Pessoa de Nível Superior - Brasil (CAPES) em 2018 - objetiva demonstrar a importância da educação sobre as temáticas de gênero e diversidade sexual, aqui denominada Educação em Gênero e Diversidade Sexual, para a promoçáo do respeito à diferenças desde a escola, enfrentando práticas discriminatórias como o bullying e outros tipos de violência, na busca por integração social, acesso a espaço e a direitos: à cidadania (ARENDT, 2012, p. 403) para todos, considerando que a norma punitiva que condena o crime, sozinha, pode não ter força suficiente para alterar a cultura LGBTIfóbica historicamente construída.

Para tanto, o material de caráter descritivo, bibliográfico e documental, fundamenta-se no seguinte problema de pesquisa: qual a contribuição da Educação em Gênero e Diversidade Sexual para o enfrentamento do bullying nas escolas e promoção da mudança social sobre o gênero e a diversidade perante a criminalização da LGBTIfobia?

O texto está fragmentado em três segmentos. Inicialmente, ocupa-se em discutir a importância do direito à igualdade pela diferença (SANTOS, 2003, p. 56) para a conquista da cidadania, a fim de que seja possível, em um segundo momento, a análise qualitativa dos efeitos do bullying LGBTIfóbico em uma perspectiva de Direitos Humanos: seja na construção das identidades dissidentes, seja na efetivaçáo de uma sociedade baseada na promoçáo da igualdade de oportunidades e de integraçáo e acesso ao espaço público, consolidando o respeito à diversidade e uma cultura democrática e cidadã (BRASIL, 2007a, p. 11). Por fim, aborda-se a Educação em Gênero e Diversidade Sexual, na qualidade de educação em Direitos Humanos, como alternativa de enfrentamento das práticas discriminatórias na escola e suas possíveis consequências, sob a perspectiva de criminalização da LGBTIfobia. 
Como primeiros resultados da pesquisa, constata-se que a Educação em Gênero e Diversidade Sexual nas escolas, por vezes tida como política educacional ideológica e subversiva, ao contrário da criminalização que não tem o condão de alterar a cultura LGBTIfóbica, poderia, a partir do diálogo e difusão de informaçóes acerca das múltiplas manifestaçóes de gênero e sexualidade, reconhecer identidades muitas vezes dissidentes, buscar a igualdade entre os gêneros, desconstruindo estereótipos e dando autonomia ao gênero feminino; enfrentar cultura do estupro e da violência contra a mulher, do abuso infantil e da gravidez precoce; combater a LGBTIfobia; rever privilégios; e, de fato, incluir minorias.

Destaca-se que pesquisa tem por fim propor reflexôes interdisciplinares ${ }^{7}$ sobre o gênero e a sexualidade em interface com o Direito e a Educação, reunindo informações que possibilitem futuros estudos acerca do tema, bem como ressaltar a importância da criação de ações e políticas públicas por parte dos órgãos públicos, que defrontem práticas discriminatórias nos ambientes escolares, considerando ser este, também, um dos propósitos da Educação em Direitos Humanos.

\section{Cidadania e igualdade pela diferença}

De acordo com Piovesan (2016, p. 534-535), o discurso jurídico da cidadania em uma perspectiva de Direitos Humanos sempre esteve relacionado aos valores de igualdade e liberdade. Nas primeiras Declaraçóes, redigidas com base no discurso liberal da cidadania e em resistência à opressão do período, predominaram previsóes acerca de direitos civis e políticos (direitos de liberdade) e a ausência de intervençáo estatal. A partir do advento do discurso social da cidadania, influenciado pela concepção marxista-leninista e objetivando eliminar a exploração econômica e incentivar as prestaçôes estatais, surgem os direitos sociais, econômicos e culturais (direitos de igualdade).

A Declaração Universal dos Direitos Humanos (DUDH), por sua vez, inova ao combinar tanto direito civis e políticos (arts. $3^{\circ}$ a 21 ), quanto direitos sociais, econômicos e culturais (arts. 22 a 28) e estabelecer a ideia de que os Direitos Humanos são universais e inerentes à dignidade humana (AGNU, 1948). A concepção contemporânea da cidadania, portanto, além de combinar direitos de liberdade e de igualdade, universalizando-os, ainda é integrada pelo "processo de especificação do sujeito" (PIOVESAN, 2016, p. 536). Sobre esse novo componente que foi incorporado à compreensão jurídica da cidadania, observa-se que:

7 Direito e Educação, nessa perspectiva, necessitam ser combinados para que se solidifiquem valores de Direitos Humanos e novas condutas capazes de superar diferentes discriminaçóes sejam assumidas pelos cidadãos desde a escola. 
A partir dele, o sujeito de direito deixa de ser visto em sua abstração e generalidade e passa a ser concebido em sua concretude, em suas especificidades e peculiaridades. Daí falar-se na tutela jurídica dos direitos das mulheres, crianças, grupos raciais minoritários, refugiados, etc., isto é, aponta-se não mais ao indivíduo genérica e abstratamente considerado, mas ao indivíduo "especificado", com base em categorizaçoos relativas ao gênero, idade, etnia, raça, etc. (PIOVESAN, 2016, p. 536).

Nessa perspectiva, o alcance da cidadania plena deve contemplar, simultaneamente, acesso ao direito de liberdade, de igualdade e de ter respeitadas as características que individualizam e diferenciam quem você é: a cor de sua pele, sua deficiência física e mental, o gênero que você reconhece para si e expressa, o nome que prefere, por quem você se atrai afetiva e sexualmente, sua condição de estrangeiro, sua idade etc. Cidadania, assim, envolve o acesso a direitos civis, políticos, sociais, econômicos, culturais e de diferença, razão pela qual sua vinculação às discussóes jurídicas e políticas são constantes e a atuação estatal é essencial para que ela se efetive.

Arendt (2012, p. 403) sintetiza essa interpretação como o "direito a ter direitos", o direito de cada pessoa de estar integrada e ter acesso ao espaço público de um Estado que beneficia seus cidadãos com direitos, enquanto exige o cumprimento de obrigaçóes. Nesse sentido, Lafer (1988, p. 22) explora:

A cidadania é o direito a ter direitos, pois a igualdade em dignidade e direitos dos seres humanos não é um dado. É um construído da convivência coletiva, que requer o acesso ao espaço público. É este acesso ao espaço público que permite a construção de um mundo comum através do processo de asserção dos direitos humanos.

Essa relação entre liberdade, igualdade e diferença é sintetizada por Santos (2003, p. 51) ao abordar a questâo da desigualdade:

[...] temos o direito a ser iguais quando a nossa diferença nos inferioriza; e temos o direito a ser diferentes quando a nossa igualdade nos descaracteriza. Daí a necessidade de uma igualdade que reconheça as diferenças e de uma diferença que não produza, alimente ou reproduza as desigualdades.

Ao destacar a necessidade de reconhecimento da diferença para, a partir dela, náo produzir e/ou reproduzir desigualdades, Santos (2003) apresenta um modelo de igualdade que está vinculado ao direito de ser diferente, o direito de desviar dos 
padróes naturalizados e tidos como normais. Essa valorização da diferença supera a ideia de que a igualdade do Estado é medida por um denominador comum que percebe todas as pessoas de maneira genérica e sem qualquer distinção, correspondendo à concepção contemporânea de cidadania de Piovesan (2016).

Com o intuito de se alcançar a integração social a partir da efetivação da cidadania plena (que reconhece e respeita as diferenças), a garantia da inclusão das pessoas que são lesadas em direito ou dignidade em razão de ser diferente, nos mais diversos espaços públicos e privados. A cidadania acontece quando a diferença - como elemento identitário - é respeitada nos ambientes educacional, laboral, social, cultural, econômico, político, permitindo o acesso a espaços públicos e ao convívio social e fortalecendo a liberdade de ir e vir de e ser quem se é. Promover o respeito à diversidade é indispensável à consagração dos Direitos Humanos, pois possibilita a "[...] atuação do ser humano como um agente autônomo" (MOREIRA, 2017b, p. 242).

No que se refere especificamente à diversidade de gênero e sexualidade, a fim de consagrar o direito à não discriminação, os Princípios de Yogyakarta, importante documento internacional que versa sobre a aplicação da legislação internacional de Direitos Humanos em relação à identidade de gênero e orientação sexual, prevê que:

Todas as pessoas têm o direito de desfrutar de todos os direitos humanos livres de discriminação por sua orientação sexual ou identidade de gênero. Todos e todas têm direito à igualdade perante a lei e a proteçấo da lei sem qualquer discriminação, seja ou não também afetado o gozo de outro direito humano. A lei deve proibir qualquer dessas discriminaçôes e garantir a todas as pessoas proteção igual e eficaz contra qualquer uma dessas discriminaçôes. A discriminação com base na orientação sexual ou identidade gênero inclui qualquer distinção, exclusão, restrição ou preferência baseada na orientação sexual ou identidade de gênero que tenha o objetivos (sic) ou efeito de anular ou prejudicar a igualdade perante a lei ou proteçáo igual da lei, ou o reconhecimento, gozo ou exercício, em base igualitária, de todos os direitos humanos e das liberdades fundamentais. A discriminação baseada na orientação sexual ou identidade de gênero pode ser, e comumente é agravada por discriminação decorrente de outras circunstâncias, inclusive aquelas relacionadas ao gênero, raça, idade, religiấo, necessidades especiais, situação de saúde e status econômico (BRASIL, 2007b, p. 12-13, grifo nosso). 
Já no Brasil, além inexistência de produçóes legislativas que tutelem direitos a pessoas LGBTI, pela análise dos índices de violência contra essa população no país ${ }^{8}$, percebe-se que a não observância ao respeito às diferenças tem acarretado na manutenção de ameaças ou violaçôes a Direitos Humanos contra indivíduos que são percebidos hierarquicamente como inferiores pela sociedade brasileira em razão do gênero que expressam e reconhecem para si (identidade) e da orientação sexual (comportamento afetivo e sexual) que adotam. Pessoas LGBTI têm mais dificuldade de integração ao meio social e, no caso das travestis, por exemplo, pode afirmar-se que há um interesse social em sua completa marginalização.

Considerando que, conforme pontua Butler (2003, p. 25), o gênero é uma construçáo social, é preciso destacar que a cultura hétero e cisnormativa, massivamente difundida, também se apresenta como óbice à não discriminação e ao respeito às diferenças, pois abarca, em conjunto com a normalidade, apenas condutas não desviantes do padrão heterossexual, binário e cisgênero. Sobre esse controle da sexualidade e padronização do gênero, Balestrin (2018, p. 22) destaca:

Numa lógica binária do sexo, gênero e sexualidade, um corpo de homem deverá, necessariamente, constituir-se enquanto um corpo masculino e, para seguir a norma, deverá desejar outro corpo do sexo oposto e feminino. Da mesma forma, o corpo de mulher deverá ser feminino e desejar outro corpo masculino. Esta é a chamada heteronormatividade - uma norma que opera na direção de uma "heterossexualidade compulsória". Essa norma faz crer que a heterossexualidade é a forma mais natural, normal e saudável de viver a sexualidade. Quando um sujeito foge a essa norma, ele é tido como desviante, anormal, doente, incompleto, imaturo.

Como consequência disso, o indivíduo que sofre discriminação acaba sendo privado de acessar espaços e gozar direitos, ou seja, de alcançar sua cidadania plena. Com isso, perde também a democracia, considerando que a Constituição de 1988, em seu artigo 5º, garante a inviolabilidade do direito à liberdade e à igualdade, como direitos fundamentais, vedando, ainda, qualquer forma de discriminaçãoo (BRASIL, 1988).

Assim, o que se busca com o respeito às diferenças, na verdade, é alcançar a liberdade e igualdade como direitos, mas também garantir o desenvolvimento identitário de cada indivíduo, para que todas as pessoas, sem distinção, sejam

8 No que se refere à discriminação por orientação sexual e identidade de gênero, os dados de violência contra a comunidade LGBTI constatam que no Brasil morreram 445 pessoas, em 2017, vítimas da homotransfobia: 387 assassinatos e 58 suicídios. Um aumento de $30 \%$ em relação a 2016, quando foram registradas 343 mortes, segundo o Grupo Gay da Bahia (GGB, 2018). 
integradas ao convívio social e possam ocupar os espaços a que têm direito, superando eventuais processos de exclusão. No que se refere às pessoas LGBTI, é preciso descontruir estigmas e normas criadas sobre o gênero e a sexualidade, a ponto de incluir todas as pessoas do modo como elas são e garantir-lhes a vivência plena de sua cidadania.

\section{Bullying contra alunos LGBTI na escola: um problema de cidadania?}

Como explorado no item anterior, a discriminação contra pessoas LGBTI, além de limitar as liberdades individuais, também prejudica a integração social e o respeito às diferenças, uma vez que os indivíduos afetados pela imposição forçada de um padrão hétero e cisnormativo, recorrentes vítimas de discriminação ${ }^{9}$, em quase a totalidade dos espaços que convive, têm ameaçados seu pleno desenvolvimento e, também, a conquista de suas cidadanias (ARENDT, 2012, p. 403).

Verificando-se a relação entre LGBTIfobia e ambiente escolar, constitucionalmente (BRASIL, 1988) estabeleceu-se que a educação brasileira será promovida "[...] visando ao pleno desenvolvimento da pessoa, seu preparo para o exercício da cidadania e sua qualificação para o trabalho". Com isso, a fim de que sejam consagrados os preceitos constitucionais supramencionados, especialmente acerca da obrigação de formar para a cidadania e possibilitar o pleno desenvolvimento na escola, é necessário que o ambiente escolar seja, simultaneamente, libertador, igualitário e aberto à diferença. É o que também postula o Plano Nacional de Educação em Direitos Humanos (PNEDH):

O Estado brasileiro tem como princípio a afirmação dos direitos humanos como universais, indivisíveis e interdependentes e, para sua efetivação, todas as políticas públicas devem considerá-los na perspectiva da construção de uma sociedade baseada na promoçấo da igualdade de oportunidades e da equidade, no respeito à diversidade e na consolidaçấo de uma cultura democrática e cidadã (BRASIL, 2007a, p. 11).

Em igual sentido, as Diretrizes Nacionais para a Educação em Direitos Humanos (BRASIL, 2013, p. 11) dispóem que:

Para que seja consolidada, a Educação em Direitos Humanos necessita da participação dos profissionais do ensino, da sociedade

9 Moreira (2017a, p. 21) observa que a discriminação tem uma dimensão coletiva, que demanda a atuaçấo de um grupo (majoritário) em prejuízo de outro (minoritário), socialmente percebido como inferior e ocorrerá quando, embora sem intenção de ferir alguma norma jurídica, houver algum tipo de prejuízo ao status cultural e status material de uma pessoa (MOREIRA, 2017a, p. 196-197). 
civil, dos agentes e representantes políticos. A ED trabalha com orientação de crianças, jovens e adultos para que assumam suas responsabilidades enquanto cidadãos, promovendo o respeito entre as pessoas e suas diferenças, fazendo com que reconheçam seus direitos e defendam os direitos dos outros.

A diferença está presente na escola, sejam elas instituiçóes públicas ou privadas; federais, estaduais ou municipais; localizada nos grandes centros ou voltada a atender longínquas comunidades no meio rural. A diferença está presente porque é nela que se fundamenta a identidade. E a negação da identidade é a inviabilização do ser. Quando uma identidade não é aceita em razão de determinada diferença, inicia-se o processo social de exclusão, estimulado pelo interesse coletivo de invisibilização, dominação ou eliminação dessa diferença.

$\mathrm{Na}$ escola, a reação mais comum de ataque à diferença é o bullying. De acordo com Pereira, Varela e Silveira (2015, p. 1491): “O bullying é uma palavra originária do inglês - sem tradução equivalente no Brasil - cuja denominação reflete um conjunto de comportamentos antissociais, agressivos e reiterados com o intuito de maltratar, oprimir e humilhar determinada pessoa ou um grupo de pessoas."

Quando o bullying se torna ferramenta para a LGBTIfobia nas escolas, inicia-se um processo de mecanização da opressão à diferença, reforçando homofobia ${ }^{10}$, transfobia $^{11}$ e a discriminação a qualquer desvio do padrão hétero e cisnormativo. A violência psicológica e mesmo física contra pessoas LGBTI é evidenciada por sentimentos de baixa estima, medo, ansiedade, vingança e a perda dos estímulos para frequentar o ambiente escolar, interagir com colegas, perguntar e expor pensamentos em sala de aula, ocasionando a diminuição do ou mesmo a evasão escolar.

Desse modo, o PNEDH traz como meta para a Educação em Direitos $\mathrm{Hu}-$ manos, entre outras:

[...] 9. fomentar a inclusão, no currículo escolar, das temáticas relativas a gênero, identidade de gênero, raça e etnia, religiáo,

10 "A homofobia gera e está presente em insultos, ofensas e caricaturas sobre os papéis de gênero (por exemplo, de homens afeminados e mulheres masculinizadas), chegando até a violência física - letal em determinados casos - sofrida por gays e lésbicas e por travestis. As agressóes homofóbicas produzem reiteradamente no indivíduo agredido e na sua comunidade de pares a inferiorização. Operam como injúrias que se inscrevem no corpo e na memória da pessoa, formando a personalidade do indivíduo e a consciência coletiva. [...] A homofobia não só afeta a quem manifesta uma expressấo de gênero diferente da esperada - e de quem se suspeita ter um desejo desviado, portanto, perigoso - mas também a todos os meninos, meninas e jovens que sofrem o terror de serem acusados de homossexuais. A homofobia instaura um regime de controle da conduta sexual e de adaptaçáo aos padrốes de gênero dominantes, presente na formação de todas e todos" (BRASIL, 2009, p. 152).

11 Já a transfobia "[...] representa uma das expressóes mais violentas e nocivas da hostilidade por preconceito sexual. Enquanto os homens e as mulheres homossexuais têm a possibilidade de manter sua orientação em segredo - o que é frequentemente vivido como uma condenação ao silêncio - no caso das travestis (e, em certa medida, dos e das transexuais), acontece o inverso: pela sua expressão de gênero, elas estão permanentemente expostas a agressōes" (BRASIL, 2009, p. 153). 
orientação sexual, pessoas com deficiências, entre outros, bem como todas as formas de discriminação e violaçōes de direitos, assegurando a formação continuada dos(as) trabalhadores(as) da educação para lidar criticamente com esses temas (BRASIL, 2007a, p. 33, grifo nosso).

Em que pese o reconhecimento da importância de incluir a abordagem das temáticas envolvendo recortes de gênero e diversidade sexual nos currículos escolares desde 2007, quando foi publicado do PNEDH (BRASIL, 2007a), a Pesquisa Nacional sobre o Ambiente Educacional no Brasil, a fim de relatar as experiências de adolescentes e jovens lésbicas, gays, bissexuais, travestis e transexuais nos ambientes educacionais, constatou que:

[...] $73 \%$ foram agredidos/as verbalmente por causa de sua orientaçấo sexual. $68 \%$ foram agredidos/as verbalmente na escola por causa de sua identidade/expressão de gênero. $27 \%$ dos/ das estudantes LGBT foram agredidos/as fisicamente por causa de sua orientaçáo sexual. 25\% foram agredidos/as fisicamente na escola por causa de sua identidade/expressão de gênero. $56 \%$ dos/ das estudantes LGBT foram assediados/as sexualmente na escola (ABGLT, 2016, p. 19).

Pereira, Normanton e Stempliuk (2018, p. 15) também apresentam dados sobre o perfil da discriminação entre os atores que interagem nos ambientes escolares:

De acordo com a pesquisa Preconceito e Discriminação no Ambiente Escolar, realizada pela Fundação Instituto de Pesquisas Econômicas a pedido do Instituto Nacional de Estudos e Pesquisas Educacionais Anísio Teixeira (Inep), 94,2\% têm preconceito étnico-racial, $93,5 \%$ de gênero, $87,5 \%$ socioeconômico e $87,3 \%$ com relaçấo à orientação sexual, entre outras percepçôes de preconceitos.

Nesse prisma, há que se destacar a importância do envolvimento dos agentes educacionais para a desnaturalização da inferiorização da diferença na escola, problematizando-a em vez de tolerá-la ou omitir-se diante dela, observando-se, sobretudo, que:

[...] a escola inclui e exclui de acordo com padróes fabricados de normalidade/anormalidade, competência/incompetência, aptidão/inaptidáo, elementos muitas vezes ancorados em dados 
biológicos e/ou econômicos, como a cor da pele, o sexo e a classe a que pertencem.

A prática do bullying contra pessoas LGBTI tem causas estruturais que precisam ser problematizadas. Os agentes educacionais necessitam assimilar que, à parte dos prejuízos pedagógicos, a omissão institucional diante de atitudes humilhantes e discriminatórias com base em gênero e orientação sexual, contraria liberdades individuais e garantias constitucionais, direitos da criança e adolescente ${ }^{12} \mathrm{e}$ o caráter democrático da escola. A diferença, pelo contrário, poder servir convenientemente para ensinar e aprender, a partir da assimilação de novos conceitos e da troca de experiências relatadas por quem sofre por ser diferente. Nesse sentido, caminha Aguilera Urquiza (2016, p. 21, grifo nosso) ao afirmar que:

Nesse contexto de interaçáo entre os diferentes, sejam eles indivíduos, grupos ou sociedades, um elemento fundamental é o processo educacional, espaço onde as geraçôes assumem, através da escola, o dinâmico processo de transmissão cultural e formação de novos elementos e padróes culturais. A escola é o espaço privilegiado para a desconstrução e construção de novas práticas culturais e identitárias. Advém desse papel privilegiado a aposta das políticas públicas sobre a diversidade, direitos humanos e outros, centrados no processo educacional. A educação torna-se, dessa forma, um Direito Humano fundamental. $\mathrm{O}$ acesso ou não a esse direito atua, ora como causa ora como consequência da pobreza e exclusão social.

A escola está intrinsicamente vinculada à conquista da cidadania por sua capacidade de gerar ao cidadão reflexôes sobre privilégios e desigualdades, na qualidade de indivíduos inseridos em um meio social composto por diferenças, no qual todos têm o direito de fazer parte. A educação é capaz de proporcionar aos educandos a empatia necessária para conhecer uma dimensão maior do mosaico cultural-econômico-social-político-ambiental-histórico em que se vive e a importância de se respeitar a condiçáo humana do outro, a identidade que o caracteriza como é, algo que não se pode deixar de ser sem negar a si mesmo. Todavia,

[...] um dos principais pontos de tensão no espaço escolar ainda é a visibilidade dos sujeitos que escapam das normas, promovendo a diversidade. Refiro-me, principalmente, a sujeitos que transitam pelas posiçóes de feminilidade e masculinidade e aos sujeitos que

12 O Estatuto da Criança e do Adolescente (BRASIL, 1990), dispóe que "é dever de todos velar pela dignidade da criança do adolescente, pondo-os a salvo de qualquer tratamento desumano, violento, aterrorizante, vexatório ou constrangedor". 
experimentam os prazeres fora da sexualidade normativa, ou seja, da heterossexualidade (FRIEDERICHS, 2018, p. 71).

Por conta disso, é mister a intervenção do Estado Democrático, transformador da realidade social, para que introduza novas e eficazes conjunturas políticas a fim de transfigurar o atual panorama social e jurídico, voltando o olhar dos agentes públicos às ameaças e violaçôes a Direitos Humanos perpetradas com base em LGBTIfobia, bem como eliminar o bullying discriminatório dos ambientes escolares (PEREIRA; VARELA; SILVEIRA, 2015, p. 1495).

\section{Educação em gênero e diversidade sexual: uma alternativa de enfrentamento?}

Além dos prejuízos à vítima, os efeitos do bullying com base em discriminação de gênero e orientação sexual podem atingir outros educandos quando passam a representar a naturalização da violência verbal, física e psicológica e levam à fixação de estigmas que reforçam a hierarquização entre identidades e comportamentos afetivos e sexuais. O bullying, quando vivenciado e não problematizado na escola, mantém a ideia de que pessoas LGBTI são naturalmente inferiores e que, por isso, é aceitável que sejam lesadas em direitos, marginalizadas de espaços e invisilizadas no convívio social, especialmente quando houver a combinação de outros recortes também inferiorizados nas relações entre diferenças.

Se é objetivo da escola preparar o cidadão que integrará a sociedade, quando o bullying se manifesta como LGBTIfobia em diferentes espaços públicos e privados, deixa de ser um problema exclusivamente educacional e passa a ser social. A relação intrínseca entre educação, família, sociedade e Estado trazida na Constituição (BRASIL, 1988) tornam necessários o envolvimento de diferentes instituiçôes e a movimentação da máquina pública para a garantia de segurança e dignidade humana para pessoas LGBTI. Nesse sentido,

A escola é, portanto, influenciada pelos modos de pensar e de se relacionar $\mathrm{da} /$ na sociedade, ao mesmo tempo em que os influencia, contribuindo para suas transformaçóes. Ao identificarmos o cenário de discriminaçóes e preconceitos, vemos no espaço da escola as possibilidades de particular contribuição para alteração desse processo. A escola, por seus propósitos, pela obrigatoriedade legal e por abrigar distintas diversidades (de origem, de gênero, sexual, étnico-racial, cultural etc.), torna-se responsável - juntamente com estudantes, familiares, comunidade, organizaçóes governamentais e não governamentais - por construir caminhos 
para a eliminação de preconceitos e de práticas discriminatórias. Educar para a valorização da diversidade não é, portanto, tarefa apenas daqueles/as que fazem parte do cotidiano da escola; é responsabilidade de toda a sociedade e do Estado (BRASIL, 2009, p. 31).

A ordem pública, todavia, tem posicionado as questôes de gênero e diversidade sexual como conteúdos políticos de esquerda, e não de Direitos Humanos; com intençóes subversivas, impulsionadas por uma "Ideologia de Gênero" que teria sido especialmente criada para destruir a instituição familiar e ameaçar a moralidade estatal. Balthazar (2018, p. 157), sobre esse ponto, destaca que:

No cenário contemporâneo, observamos um recrudescimento de um fascismo micropolítico, mobilizado por um grande número de indivíduos que, no limite, são incapazes de se abrir à relação com o outro e à possibilidade de, nessa mesma relaçẫo, ser mobilizados a pensar diferentemente do que se é. Com efeito, o fascismo que habita os corpos dos indivíduos tem ganhado, em nossos dias, uma envergadura molar, mobilizando e mobilizado por figuras políticas que exercem, no âmbito da política estatal, uma série de entraves à conquista de direitos de diversos setores da sociedade. A escola se tornou, em meio a esse cenário, um espaço de disputa, em que a vocalidade política de minorias de gênero e sexuais - até há pouco vista já como estabelecida - se vê, novamente, ameaçada por uma expansão dos discursos de ódio.

Ainda que haja a previsão de conteúdos envolvendo o gênero e a sexualidade entre as metas e os objetivos do Plano Nacional de Educação (PNE) vigente (BRASIL, 2014) e nos Parâmetros Curriculares Nacionais para $1^{\mathrm{a}}$ a $4^{\mathrm{a}}$ séries (BRASIL, 1997) e Parâmetros Curriculares Nacionais para 5a a $8^{a}$ séries (BRASIL, 1998), em que sáo tratados como temas transversais ${ }^{13}$, a abordagem do gênero na escola é assunto polêmico. Sobre o assunto, Rodrigues Neto, Nozu e Rocha (2019, p. 90) destacam:

A escola, a partir disso, foi inserida na disputa antagônica entre discussóes consideradas ora mais conservadoras, ora mais

13 De acordo com os Parâmetros Curriculares Nacionais, "O compromisso com a construção da cidadania pede necessariamente uma prática educacional voltada para a compreensão da realidade social e dos direitos e responsabilidades em relação à vida pessoal e coletiva e a afirmação do princípio da participação política. Nessa perspectiva é que foram incorporadas como Temas Transversais as questôes da Ética, da Pluralidade Cultural, do Meio Ambiente, da Saúde, da Orientação Sexual e do Trabalho e Consumo. Amplos o bastante para traduzir preocupaçốes da sociedade brasileira de hoje, os Temas Transversais correspondem a questóes importantes, urgentes e presentes sob várias formas na vida cotidiana. O desafio que se apresenta para as escolas é o de abrirem-se para o seu debate" (BRASIL, 1998). 
progressistas. No que se refere especificamente a gênero e diversidade, desde a aprovaçấo do Plano Nacional de Educaçáo em 2014 (PNE), e da supressão das expressôes "gênero" e "orientação sexual" da versão final do documento, começam a aparecer indícios de uma tendência política e social de silenciamento dessas temáticas.

A Educação em Gênero e Diversidade Sexual, em contrapartida, enquanto espécie da Educação em Direitos Humanos, propóe tornar o espaço escolar um espaço mais democrático e inclusivo, no que se refere às múltiplas expressóes de gênero e diversidade sexual, considerando que:

A escola precisa estar sempre preparada para apresentar não uma verdade absoluta, mas sim uma reflexão que possibilite aos alunos e às alunas compreenderem as implicaçóes éticas e políticas de diferentes posiçôes sobre o tema e construírem sua própria opiniáo nesse debate. A ideia de que educação não é doutrinação talvez valha aqui mais do que em qualquer outro campo, pois estaremos lidando com valores sociais muito arraigados e fundamentais (BRASIL, 2009, p. 14).

Assim, a difusão das informaçooes sobre sexualidade, construçōes/expressões de gênero e diversidade sexual, respeitados os critérios pedagógicos ${ }^{14}$ e etários recomendados, é alternativa para ensinar o respeito às diferenças que convivem no espaço escolar. Para Louro (2000, p. 31):

[...] na escola, pela afirmação ou pelo silenciamento, nos espaços reconhecidos e públicos ou nos cantos escondidos e privados, é exercida uma pedagogia da sexualidade, legitimando determinadas identidades e práticas sexuais, reprimindo e marginalizando outras.

\section{No mesmo sentido, o PNEDH (2007, p. 22) estabelece que as políticas públicas para Direitos Humanos devem estar focadas em atingir:}

a) o incremento da sensibilidade e da consciência sobre os assuntos globais por parte de cidadáos(âs) comuns; b) a institucionalizaçấo de um padrão mínimo de comportamento nacional e internacional dos Estados, com mecanismos de monitoramento, pressão e sanção; c) a adoção do princípio de empoderamento

\footnotetext{
14 Importante frisar que o presente artigo analisa o tema pelo viés jurídico, não discutindo o mérito pedagógico acerca do papel e dos meios que as escolas dispóem para a tratativa dos temas de gênero e diversidade sexual nas salas de aula. Contudo, reconhece-se a relevância do debate, a fim de que as limitaçóes estruturais e profissionais sejam suscitadas e de que estratégias educacionais possam ser, conjuntamente, delineadas em vista desse propósito.
} 
em benefício de categorias historicamente vulneráveis (mulheres, negros(as), povos indígenas, idosos(as), pessoas com deficiência, grupos raciais e étnicos, gays, lésbicas, bissexuais, travestis e transexuais, entre outros); d) a reorganização da sociedade civil transnacional, a partir da qual redes de ativistas lançam açóes coletivas de defesa dos direitos humanos (campanhas, informaçôes, alianças, pressóes etc.), visando acionar Estados, organizaçóes internacionais, corporaçôes econômicas globais e diferentes grupos responsáveis pelas violaçóes de direitos.

Desse modo, educar em gênero e diversidade sexual para o enfrentamento, entre outros, do bullying LGBTIfóbico possibilita que se olhe:

[...] a diferença sem ter a necessidade de enquadrá-la em classificaçôes binárias e em escalas hierárquicas que atribuem valores aos corpos conforme a cor da pele, o sexo anatômico, a posição de gênero assumida, a sexualidade experimentada. Apenas assim poderemos trabalhar para combater as desigualdades e quaisquer outras formas de discriminação, visibilizando (e não hierarquizando) as diferenças na escola (FRIEDERICHS, 2018, p. 71).

Além disso, considerando que a prática do bullying homofóbico, muitas vezes, é vista como natural e é aceita pelos próprios educadores e demais agentes educacionais, é preciso elaborar estratégias de formação continuada que envolva toda a equipe técnica. Nessa perspectiva, Lins, Machado e Escoura (2016, p. 76) afirmam que:

[...] a formação continuada de professoras/es, gestoras/es e toda a equipe técnica deve estar voltada para a percepção das questôes de gênero. Em se tratando e práticas naturalizadas em nosso cotidiano, é importante que muita e energia e esforço contínuo sejam despendidos no questionamento de nossas ações e preconceitos, visando construir uma escola mais acolhedora.

E, prosseguem:

A educação, se comprometida com a igualdade social e a inclusão, pode vir a ser um caminho privilegiado para a emancipaçáo. Por esse motivo, profissionais da educação têm um lugar privilegiado de mudança social, quando engajados na transformaçáo de preconceitos e discriminaçóes. São eles que nos educam nas mais diversas formas de conhecimento: com letras, palavras, números, histórias, afetos e valores (LINS; MACHADO; ESCOURA, 2016, p. 102). 
Pensar o espaço escolar como ferramenta para o enfrentamento à raiz de diferentes problemas econômicos e sociais é pensar a educação também como determinante para a integração social. Em função disso, a escola deve ser democrática no acesso, uma vez que $\boldsymbol{e}$ para todos; nas fontes de conhecimento, privilegiando diferentes opiniôes e áreas do saber; e em sua postura institucional, sempre pautada no diálogo, inclusão e respeito.

Diante da criminalização da LGBTIfobia pelo STF (BRASIL, 2019),

Faz-se necessário combinar proibição da discriminação com políticas compensatórias que acelerem a igualdade enquanto processe. Isto é, para assegurar a igualdade não basta apenas proibir a discriminação, mediante legislação repressiva. São essenciais as estratégias promocionais capazes de estimular a inserção e inclusão de grupos socialmente vulneráveis nos espaços sociais. [...] $\mathrm{O}$ que se percebe é que a proibição da exclusão, em si mesma, não resulta automaticamente na inclusão. Logo, não é suficiente proibir a exclusão, quando o que se pretende é garantir a igualdade de fato, com a efetiva inclusão social de grupos que sofreram e sofrem um consistente padrão de violência e discriminação (PIOVESAN, 2016, p. 339).

Com isso, percebe-se que a Educação em Gênero e Diversidade Sexual pode vir a ser uma alternativa de enfrentamento a inúmeras práticas de intolerância que ocorrem no ambiente escolar, perpetradas com base em discriminaçáo de gênero e diversidade sexual, tornando-se capaz de alcançar a transformaçáo cultural que a criminalização da LGBTIfobia, por si só, não consegue atingir.

Não há que se olvidar também que, em que pese o recorte do presente material abordar especificamente o bullying contra pessoas LGBTI - em razão de uma possível penalização caso haja o enquadrado como LGBTIfobia - a misoginia, as epidemias de doenças sexualmente transmissíveis, gestaçóes não planejadas, discriminaçóes por características econômicas, étnico-raciais e sobre condiçôes físicas e mentais, etc. são alguns outros exemplos de problemas escolares causados pela deficiência de informação e naturalização de processos opressores da diferença.

\section{Conclusão}

A consolidaçáo da Democracia, a partir da perspectiva do gênero e da sexualidade, necessita expandir os índices de inserção social e promover o respeito às diferenças em todas as instituiçóes e os diferentes atores públicos e privados que compóem o tecido social. Cidadania, nessa perspectiva, é o ter direitos (ARENDT, 
2012, p. 403), está amparada sobre direitos civis, políticos, culturais, econômicos e sociais e se constrói a partir do processo de particularizaçáo do sujeito portador desses direitos, respeitando as características que compóem sua individualidade (PIOVESAN, 2016, p. 536).

A prática do bullying discriminatório com base em gênero e orientação sexual nos ambientes escolares é óbice à formação para a cidadania, um dos objetivos traçados para a educação brasileira (BRASIL, 1988). Na perspectiva da vítima, significa ofensa a sua identidade e liberdade sexual (não necessariamente combinadas), ocasionando prejuízos ao desenvolvimento pleno (educacional, cognitivo, social, em curto prazo; e de cunho econômico, laboral, cultural e político, em médio prazo). Na perspectiva do ofensor e dos alunos que se testemunham a discriminação, há a naturalização da violência e aceitação da dominação como algo naturalmente estabelecido, uma vez que as causas estruturais que hierarquizam a diferença deixam de ser apropriadamente problematizadas.

A Educação em Gênero e Diversidade Sexual nas escolas, por vezes tida como política educacional polêmica e subversiva, pode servir como alternativa de enfrentamento da cultura LGBTIfóbica que se faz presente em diferentes espaços, mas especialmente na escola. No local onde a diferença é conteúdo vivo, capaz de ensinar e aprender, o diálogo e difusão de informaçóes acerca das múltiplas manifestaçôes de gênero e da sexualidade pode expandir sensação de pertencimento, de dignidade e de cidadania para pessoas LGBTI que estejam em situação de vulnerabilidade em termos de Direitos Humanos.

Além disso, há que se destacar que o período escolar é quando o Estado atua mais ativamente para definir o modelo de cidadáo que se quer formar e preparar à interação entre o coletivo social. Ao ensinar sobre o respeito à diferença desde o início da vida escolar, além de superar o bullying LGBTIfóbico, revendo as causas estruturais da discriminação, a escola pode ensinar como (con)viver respeitosamente com a diferença.

O bullying contra pessoas LGBTI, por sua vez, necessita ser percebido e enfrentado como violação a diferentes Direitos Humanos, cujos reflexos perpassam diferentes âmbitos da vivência social do indivíduo, mas, sobretudo, lesam sobremaneira a percepção sobre a diferença. Sem a desconstrução sobre a percepção da diferença desde a escola, leis antidiscriminatórias não têm forças para gerar a inclusão. A Educação em Gênero e Diversidade Sexual, assim, pode servir como política compensatória (PIOVESAN, 2016, p. 339) impulsionar a transformação social necessária à integração social dessas pessoas. 


\section{Referências}

ABGLT - ASSOCIAÇÃO BRASILEIRA DE LÉSBICAS, GAYS, BISSEXUAIS, TRAVESTIS E TRANSEXUAIS. Pesquisa Nacional sobre o Ambiente Educacional no Brasil, 2016: as experiências de adolescentes e jovens lésbicas, gays, bissexuais, travestis e transexuais em nossos ambientes educacionais. Curitiba: ABGLT, 2016. Disponível em: http://static.congressoemfoco.uol.com.br/2016/08/IAE-Brasil-Web-3-1.pdf. Acesso em: 10 out. 2019.

AGUILERA URQUIZA, A. H. Direitos humanos, cidadania e a diversidade cultural. In: AGUILERA URQUIZA, A. H. (org.). Nascimento: os direitos humanos nas fronteiras (Brasil e Europa). Campo Grande: UFMS, 2016.

ANDRADE, S. S. Professor/a pesquisador/a: problematizando gênero e sexualidade na escola. In: SILVEIRA, C. et al. (org.). Educação em gênero e diversidade. 2. ed. Porto Alegre: UFRGS, 2018. p. 43-54. Disponível em: https://lume.ufrgs.br/ handle/10183/186154?fbclid=IwAR1KPx6qX5qrT1Nha86MYbE13KUx6eOalgrlpR_8lFILT_KzfLtd4V7DNM. Acesso em: 10 out. 2019.

ARENDT, H. As origens do totalitarismo. São Paulo: Companhia de Bolso, 2012.

AGNU - ASSEMBLEIA GERAL DAS NAÇÕES UNIDAS. Declaração Universal dos Direitos Humanos. 1948. Disponível em: http://www.mp.go.gov.br/ portalweb/hp/7/docs/declaracao_universal_dos_direitos_do_homem.pdf. Acesso em: 10 out. 2019.

BAHIA, A. G. M. F. M. Discurso de ódio homo-transfóbico vs. liberdade de expressão: é o Direito Moderno capaz de incluir a pauta da diversidade? In: RAMOS, M. M.; NICOLI, P. A. G.; ALKMIN, G. C. (org.). Gênero, sexualidade e direitos humanos: perspectivas multidisciplinares. Belo Horizonte: Initia Via, 2017.

BALESTRIN, P. A. Introdução aos estudos de gênero e sexualidade em articulação com o campo da educação. In: SILVEIRA, C. et al. (org.). Educação em gênero e diversidade. 2. ed. Porto Alegre: UFRGS, 2018. p. 11-28. Disponível em: https://lume.ufrgs.br/handle/10183/186154?fbclid=IwAR1KPx-6qX5qrT1Nha86MYbE13KUx6eOalgrlpR_81FILT_KzfLtd4V7DNM. Acesso em: 10 out. 2019.

BALTHAZAR, G. S. Em tempos fascistas, é preciso conversar com borboletas? In: SILVEIRA, C. et al. (org.). Educação em gênero e diversidade. 2. ed. Porto Alegre: UFRGS, 2018. p. 143-160. Disponível em: https://lume.ufrgs.br/handle/10183/186154?fbclid=IwAR1 KPx6qX5qrT1Nha86MYbE13KUx6eOalgrl- 
pR_8IFILT_KzfLtd4V7DNM. Acesso em: 10 out. 2019.

BRASIL. Constituição da República Federativa do Brasil de 1988. Disponível em: http://www.planalto.gov.br/ccivil_03/constituicao/constituicao.htm. Acesso em: 10 out. 2019.

BRASIL. Lei n. 8.069, de 13 de julho de 1990. Dispóe sobre o Estatuto da Criança e do Adolescente e dá outras providências. Brasília, DF: Presidência da República, 1990. Disponível em: http://www.planalto.gov.br/ccivil_03/leis/18069.htm. Acesso em: 10 out. 2019.

BRASIL. Parâmetros curriculares nacionais: apresentação dos temas transversais, ética Secretaria de Educação Fundamental. Brasília: MEC/SEF, 1997. Disponível em: http://portal.mec.gov.br/seb/arquivos/pdf/livro081.pdf. Acesso em: 10 out. 2019 .

BRASIL. Parâmetros curriculares nacionais: terceiro e quarto ciclos: apresentação dos temas transversais. Brasília: MEC/SEF, 1998. Disponível em: http://portal. mec.gov.br/seb/arquivos/pdf/ttransversais.pdf. Acesso em: 10 out. 2019.

BRASIL. Plano Nacional de Educação em Direitos Humanos. Comitê Nacional de Educaçáo em Direitos Humanos. Brasília: Secretaria Especial dos Direitos Humanos, Ministério da Educação, Ministério da Justiça, UNESCO, 2007a. Disponível em: http://portal.mec.gov.br/index.php?option=com_docman\&view=download\&alias=2191-plano-nacional-pdf\&Itemid=30192. Acesso em: 10 out. 2019.

BRASIL. Princípios de Yogyakarta. Princípios sobre a aplicação da legislação internacional de Direitos Humanos em relação à orientação sexual e identidade de gênero. 2007b. Disponível em: http://www.dhnet.org.br/direitos/sos/gays/principios_de_yogyakarta.pdf. Acesso em: 10 out. 2019.

BRASIL. Gênero e diversidade na escola: formação de professoras/es em Gênero, Orientação Sexual e Relaçôes Étnico-Raciais. Rio de Janeiro: CEPESC; Brasília: SPM, 2009. Disponível em: http:/estatico.cnpq.br/portal/premios/2014/ig/pdf/ genero_diversidade_escola_2009.pdf. Acesso em: 10 out. 2019.

BRASIL. Secretaria de Direitos Humanos da Presidência da República. Educação em Direitos Humanos: Diretrizes Nacionais. Brasília: Coordenação Geral de Educação em SDH/PR. Direitos Humanos. Secretaria Nacional de Promoção e Defesa dos Direitos Humanos, 2013.

BRASIL. Supremo Tribunal Federal. Supremo reconhece uniäo homoafetiva. 2011. Disponível em: http://www.stf.jus.br/portal/cms/verNoticiaDetalhe.asp?idConteudo=178931. Acesso em: 10 out. 2019. 
BRASIL. Supremo Tribunal Federal. STF reafirma direito de transgêneros de alterar registro civil sem mudança de sexo. 2018. Disponível em: http://www.stf.jus.br/por$\mathrm{tal} / \mathrm{cms} / \mathrm{verNoticiaDetalhe.asp?idConteudo=386930.} \mathrm{Acesso} \mathrm{em:} 10$ out. 2019.

BRASIL. Supremo Tribunal Federal. STF enquadra homofobia e transfobia como crimes de racismo ao reconhecer omissáo legislativa. 2019. Disponível em: http:// portal.stf.jus.br/noticias/verNoticiaDetalhe.. sp?idConteudo=414010. Acesso em: 10 out. 2019.

BUTLER, J. Problemas de gênero: feminismo e subversão da identidade. Rio de Janeiro: Civilização Brasileira, 2003.

FRIEDERICHS, M. Educação para a igualdade e respeito à diversidade. In: SILVEIRA, C. et al. (org.). Educação em gênero e diversidade. 2. ed. Porto Alegre: Editora da UFRGS, 2018. p. 71-86. Disponível em: https://lume.ufrgs.br/handle/10183/186154?fbclid=IwAR1KPx-6qX5qrT1Nha86MYbE13KUx6eOalgrlpR_8lFILT_KzfLtd4V7DNM. Acesso em: 10 out. 2019.

FOUCAULT, M. O sujeito e o poder. In: DREYFUS, H; RABINOW, P. (org.). Michel Foucault: uma trajetória filosófica: para além do estruturalismo e da hermenêutica. Rio de Janeiro: Forense Universitária, 1995. p. 231-249.

GGB - GRUPO GAY DA BAHIA. Mortes Violentas de LGBT no Brasil: relatório 2017. Salvador, 2018. Disponível em: https://homofobiamata.files.wordpress. com/2017/12/relatorio-2081.pdf. Acesso em: 10 out. 2019.

LAFER, C. A Reconstrução dos direitos humanos: um diálogo com o pensamento de Hannah Arendt. São Paulo: Companhia das Letras, 1988.

LINS, B. A.; MACHADO, B. F.; ESCOURA, M. Diferentes, não desiguais: a questão de gênero na escola. São Paulo: Reviravolta: 2016.

LOURO, G. L. Pedagogias da sexualidade. In: LOURO, G. L. (org.). O corpo educado. Belo Horizonte: Autêntica, 2000, p. 7-34.

MOREIRA, A. J. O que é discriminação? Belo Horizonte: Letramento, 2017a.

MOREIRA, A. J. Cidadania Sexual: estratégia para açôes inclusivas. Belo Horizonte: Arraes, 2017b.

NAÇÕES UNIDAS DO BRASIL. LGBTI. Disponível em: https://nacoesunidas. org/tema/lgbti/. Acesso em: 10 out. 2019.

PEREIRA, G. R.; VARELA, C. M.; SILVEIRA, G. P. O fenômeno do bullying homofóbico nas instituiçóes de ensino: o direito à igualdade sexual e o princípio da dignidade da pessoa humana. Revista Ibero-Americana de Estudos em Educação, 
Araraquara, v. 10, n. esp., 2015. Disponível em: https://periodicos.fclar.unesp.br/ iberoamericana/article/view/8333. Acesso em 10 out. 2019.

PIOVESAN, F. Temas de direitos humanos. 9. ed. rev., ampl. e atual. São Paulo: Saraiva, 2016.

RODRIGUES NETO, A.; NOZU, W. C. S.; ROCHA, A. C. S. Direito à educação cidadã: reflexōes sobre o Programa Escola Sem Partido. Educação em Revista, Marília, v. 20, p. 83-98, 2019. Disponível em: http://revistas.marilia.unesp.br/ index.php/educacaoemrevista/article/view/9374. Acesso em: 23 out. 2019.

SANTOS, B. S. Reconhecer para libertar: os caminhos do cosmopolitanismo multicultural. Rio de Janeiro: Civilização Brasileira, 2003. 